\title{
BMJ Open Comparing group-based acceptance and commitment therapy (ACT) with enhanced usual care for adolescents with functional somatic syndromes: a study protocol for a randomised trial
}

\author{
Karen Hansen Kallesøe, ${ }^{1}$ Andreas Schröder, ${ }^{1}$ Rikard K Wicksell, ${ }^{2}$ Per Fink, ${ }^{1}$ \\ Eva Ørnbøl, ${ }^{1}$ Charlotte Ulrikka Rask ${ }^{1,3}$
}

To cite: Kallesøe $\mathrm{KH}$, Schröder A, Wicksell RK, et al. Comparing group-based acceptance and commitment therapy (ACT) with enhanced usual care for adolescents with functional somatic syndromes: a study protocol for a randomised trial. BMJ Open 2016;6:e012743. doi:10.1136/bmjopen-2016012743

- Prepublication history for this paper is available online. To view these files please visit the journal online (http://dx.doi.org/10.1136/ bmjopen-2016-012743)

Received 20 May 2016 Revised 17 August 2016 Accepted 24 August 2016

CrossMark

For numbered affiliations see end of article.

Correspondence to Dr Karen Hansen Kallesøe; karkal@rm.dk

\section{ABSTRACT}

Introduction: Functional somatic syndromes (FSS) are common in adolescents, characterised by severe disability and reduced quality of life. Behavioural treatments such as acceptance and commitment therapy (ACT) has shown promising results in children and adolescents with FSS, but has focused on specific syndromes such as functional pain. The current study will compare the efficacy of group-based ACT with that of enhanced usual care (EUC) in adolescents with a range of FSS operationalised by the unifying construct of multiorgan bodily distress syndrome (BDS).

Methods and analysis: $A$ total of 120 adolescents aged 15-19 and diagnosed with multiorgan BDS, of at least 12 months duration, will be assessed and randomised to either: (1) EUC: a manualised consultation with a child and adolescent psychiatrist and individualised treatment plan or (2) manualised ACT-based group therapy plus EUC. The ACT programme consists of 9 modules (ie, 27 hours) and 1 follow-up meeting (3 hours). The primary outcome is physical health, assessed by an Short Form Health Survey (SF-36) aggregate score 12 months after randomisation. Secondary outcomes include selfreported symptom severity, symptom interference, depression and anxiety, illness worry, perceived stress and global improvement; as well as objective physical activity and bodily stress response measured by heart rate variability, hair cortisol and inflammatory biomarkers. Process measures are illness perception, illness-related behaviour and psychological flexibility.

Ethics and dissemination: The study is conducted in accordance with Helsinki Declaration II. Approval has been obtained from the Science Ethics Committee of the Central Denmark Region and the Danish Data Protection. The results will be sought to be published according to the CONSORT statement in peer-reviewed journals.

Discussion: This is one of the first larger randomised clinical trials evaluating the effect of a group-based intervention for adolescents with a range of severe FSS.

Trial registration number: NCT02346071; Pre-results.

\section{Strengths and limitations of this study}

- Large-scale study in an area with limited knowledge.

- Evaluation of psychosocial and biological predictors and moderators of outcomes.

- Thorough assessment of all patients providing them with evidence-based understanding of their illness.

- Assessment and treatment are carried out in a specialised setting which might affect generalisation.

- Results not automatically applicable to younger adolescents given the developmental perspective, with multiple symptoms being less common in children and younger adolescents.

\section{BACKGROUND}

Functional somatic syndromes (FSS), including chronic fatigue syndrome, juvenile fibromyalgia, functional gastrointestinal disorders and idiopathic pain syndromes, are wellknown conditions in adolescents. FSS are diagnostic unities representing clusters of related functional somatic symptoms. Prevalence rates vary considerably due to differences in case definitions, assessment instruments and study populations. ${ }^{1-3}$ Studies attempting to cover the whole range of different functional somatic symptoms suggest that $5-10 \%$ of children and adolescents in the general population are substantially affected and likely to need care. ${ }^{4} 5$ Suffering from FSS during adolescence often has high personal and societal consequences. Adolescents have a higher risk of psychosocial problems such as social isolation, longterm school absence and reduced quality of life, ${ }^{6}$ and anxiety and depression are 
common comorbidities. ${ }^{7} 8$ A substantial proportion show continuity of functional symptoms into adulthood $^{9-11}$ and are less likely to obtain a college education. ${ }^{9}$ Furthermore, adolescents diagnosed with FSS have higher overall healthcare costs due to increased use of medication and healthcare services. ${ }^{9} 12$ The aetiology of FSS remains unknown. Recent studies suggest a potential correlation between physiological stress and FSS, with physical inactivity as a potential covariate. ${ }^{13-16}$ It is proposed that a (patho)physiological response to prolonged or severe mental and/or physical stress in genetically susceptible individuals may trigger symptom development. ${ }^{17}$

High co-occurrence of different types of FSS, especially various pain syndromes, has been shown in children and adolescents. ${ }^{18-20}$ Children reporting multiple symptoms have an associated higher frequency of distress and impairment (eg, higher kindergarten/school absenteeism and consultations with physicians). ${ }^{21}$ Moreover, adult patients presenting with multiple symptoms from several organ systems have a poorer prognosis and a higher risk of chronification. ${ }^{22-24}$ Thus, an attempt to recognise the most severely affected patients with the highest illness burden may encompass sampling patients with the highest symptom load (ie, multiple symptoms from several organ systems). Recently, the empirically based unifying diagnostic category bodily distress syndrome (BDS) was introduced..$^{25}$ The diagnosis describes specific symptom patterns and includes a multiorgan subtype and four single organ subtypes; in adult samples, it has been shown to capture a range of FSS including fibromyalgia, irritable bowel syndrome, noncardiac chest pain and chronic fatigue syndrome. ${ }^{26}$ Multiorgan BDS comprising multiple symptoms from at least three specific symptom groups thus offers a diagnostic unity potentially including the most severely affected patients.

Cognitive-behavioural therapy (CBT) has been shown to reduce symptoms and increase functioning in adults with $\mathrm{FSS},{ }^{27-30}$ whereas the evidence for treatment in adolescents is sparse. Family-based CBT and internetdelivered CBT have proven effective in young patients with specific FSS. ${ }^{31-36}$ However, the development of specifically tailored treatments for each FSS or symptom profile seems to be an inefficient strategy due to the costly nature of establishing separate clinics in each medical (sub)specialty, the fragmented care available and difficulty in handling multisymptomatic patients at those clinics. ${ }^{17} 3738$ Recent studies suggest that adult patients with various FSS can feasibly receive the same treatment delivered in a group format, regardless of their main functional symptom. ${ }^{39}$ 40 In adolescents, group treatment has been widely used and shown to be feasible in the treatment of psychiatric and nonpsychiatric diseases. ${ }^{41}{ }^{42}$ Group format offers several benefits including peer modelling, diminishment of stigma, increased motivation and higher acceptance of feedback from peers as opposed to professionals. ${ }^{43}$ Hence, a unified group-based treatment may be advantageous for adolescents with various FSS due to feasibility, accessibility of treatment and potential healthcare savings.

Acceptance and commitment therapy (ACT), which derives from CBT, has shown promising results in children and adolescents with chronic functional pain. ${ }^{44}$ Evidence suggests that acceptance of pain is related to enhanced physical and emotional functioning, whereas attempts to control pain may lead to higher pain and disability. ${ }^{46} \quad 47$ By reducing avoidance behaviour and symptom interference, ACT can increase functioning and enhance quality of life, through value-driven acceptance and exposure strategies. ${ }^{48}$ Symptom avoidance seems to be a general problem leading to disability and lower quality of life in patients with FSS. ${ }^{49}$ This provides a rationale for a therapeutic approach focused on reduction of avoidance behaviour and acceptance of somatic symptoms.

The objective of the present trial is to examine the efficacy of ACT-based group therapy for adolescents with a range of FSS grouped under the unifying diagnosis of multiorgan BDS. ${ }^{17}$ To do this, we will examine physical health and a range of other outcomes including level of functioning, symptom interference and emotional distress at baseline, at different time points throughout the trial, and also at 12-month follow-up. An add-on study includes measurement of physiological stress response and physical activity level.

\section{METHODS}

\section{Design}

Single-site, non-blinded randomised controlled trial (RCT) with two conditions: (1) group-based ACT and (2) enhanced usual care (EUC). Overall study design is illustrated in figure 1.

\section{Setting}

Patients will be enlisted from the Research Clinic for Functional Disorders and Psychosomatics, situated in a general medicine setting at Aarhus University Hospital, Denmark. The department is a specialist, tertiary service with extra resources allocated for assessment and treatment of patients with debilitating functional somatic symptoms. Enrolment starts in January 2015 and the data collection is expected to be finalised in June 2019.

Prior to enrolment, an uncontrolled pilot study was performed to test the applicability of the multiorgan BDS diagnosis for this specific age group as well as the feasibility of the new group-based treatment programme. Twenty-one patients were included in the uncontrolled pilot study.

\section{Eligibility}

Eligibility criteria are multiorgan BDS, that is, at least three functional somatic symptoms from at least three symptom groups, moderate-to-severe impairment in 
Figure 1 Flow chart of participants with estimated numbers at each level. ACT, acceptance and commitment therapy; EUC, enhanced usual care; SCAN, Schedules for Clinical Assessment in Neuropsychiatry.

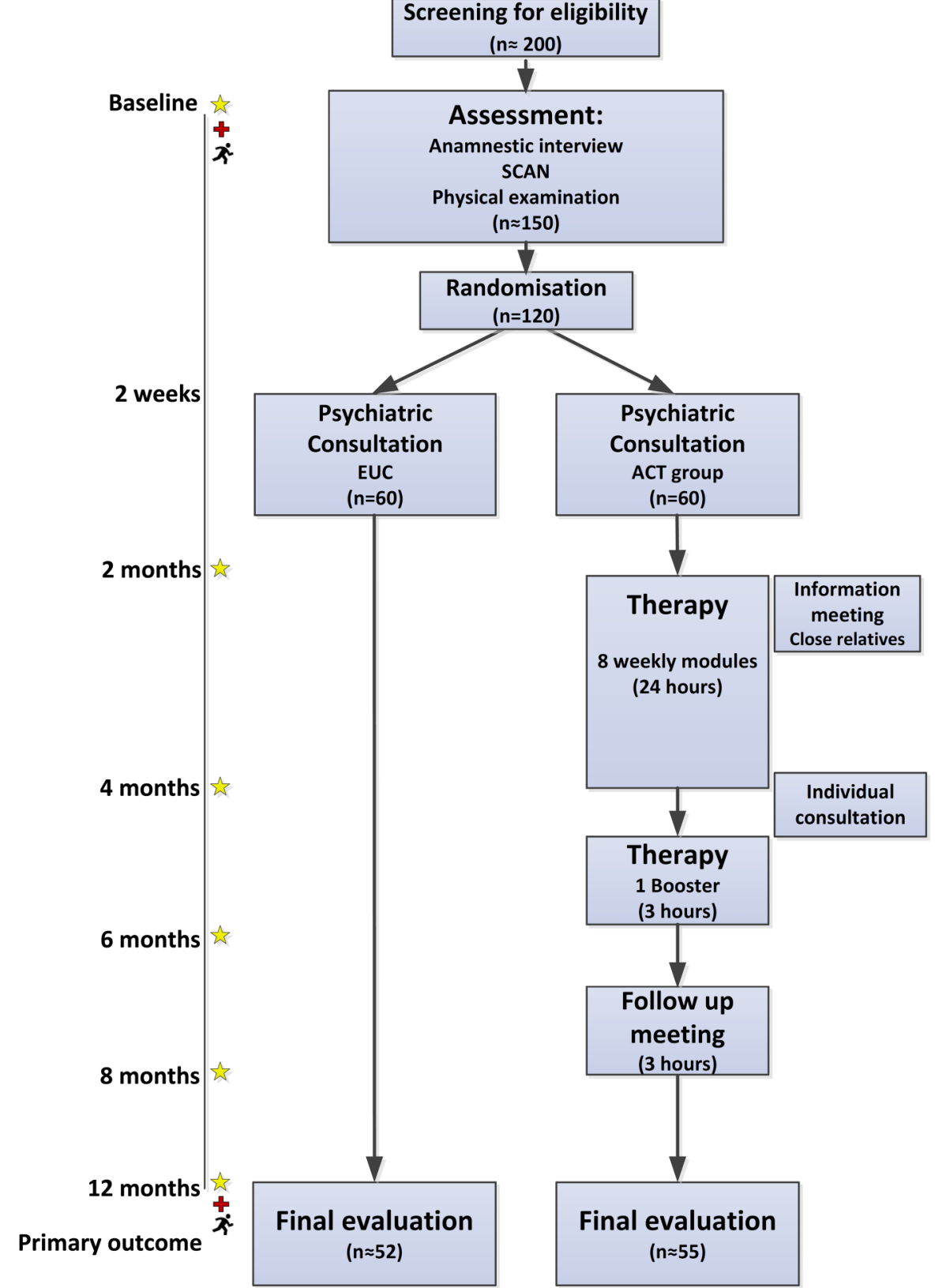

Questionnaires \& Physiological stress response daily life and symptom duration for a minimum of 12 months (table 1 ). 2226

\section{Inclusion and exclusion criteria}

The study criteria are summarised in box 1 .

\section{Recruitment procedures}

A total of 120 adolescents (aged 15-19), referred from general practitioners (GP), practising medical specialists or hospital wards, will be recruited into the trial. All referrals are initially screened for eligibility by a team of physicians from the Research Clinic for Functional Disorders and Psychosomatics.

\section{Assessment}

Patients regarded as eligible undergo a standardised clinical psychiatric and somatic assessment, performed by a physician specialised or trained in child and adolescent psychiatry. The assessment consists of a: (1) review of former discharge letters, medical records and other relevant information, (2) standardised clinical interview, (3) Schedules for Clinical Assessment in Neuropsychiatry (SCAN), ${ }^{50}$ which screens for general psychopathology and contains a detailed section on functional somatic symptoms, (4) screening for child and adolescent psychiatric disorders not covered by the SCAN, that is, attention deficit hyperactivity disorder (ADHD), autism and conduct disorder with specific 
Table 1 Diagnostic criteria for multiorgan bodily distress syndrome (BDS) 2526

\begin{tabular}{|c|c|}
\hline Gastrointestinal & $\begin{array}{l}\text { Cardiopulmonary (including } \\
\text { autonomic symptoms) }\end{array}$ \\
\hline Abdominal pain & Palpitations/heart pounding \\
\hline Nausea & Hot or cold sweats \\
\hline $\begin{array}{l}\text { Frequent loose bowel } \\
\text { movements }\end{array}$ & $\begin{array}{l}\text { Breathlessness without } \\
\text { exertion }\end{array}$ \\
\hline Diarrhoea & Hyperventilation \\
\hline Feeling bloated & Dry mouth \\
\hline Regurgitations & Trembling/shaking \\
\hline $\begin{array}{l}\text { Burning sensation in } \\
\text { chest }\end{array}$ & Churning in stomach \\
\hline Constipation & Flushing or blushing \\
\hline Vomiting & Precordial discomfort \\
\hline Musculoskeletal & General symptoms \\
\hline Muscular ache or pain & Headache \\
\hline Pain in the joints & Concentration difficulties \\
\hline $\begin{array}{l}\text { Feeling of paresis or } \\
\text { localised weakness }\end{array}$ & Impairment of memory \\
\hline Backache & Excessive fatigue \\
\hline $\begin{array}{l}\text { Pain moving from one } \\
\text { place to another }\end{array}$ & Dizziness \\
\hline $\begin{array}{l}\text { Unpleasant numbness or } \\
\text { tingling sensations }\end{array}$ & \\
\hline Pain in arms or legs & \\
\hline
\end{tabular}

sections from the child and adolescent psychiatric interview Development and Well-being Assessment (DAWBA),${ }^{51}$ (5) a clinicophysical/neurological examination and (6) standard blood tests.

Patients meeting the study criteria (see box 1) are offered participation in the study and are subsequently asked to complete the consent form before enrolment and randomisation. Figure 1 presents the flow of patients during the trial.

\section{Randomisation procedure}

Following baseline assessment, patients meeting all study criteria and consenting to participate are randomised to either EUC-based or group-based ACT. The randomisation is conducted by statisticians not involved in treatment. Permuted block randomisation with block sizes ranging from 14 to 16 made by means of a computer algorithm will be used to ensure balanced group sizes and allocation concealment. Patients consenting to participate receive an opaque envelope taken from a sequential order containing information on group allocation, ensuring that initial assessment is not influenced by group allocation.

Since the study compares a psychological treatment with EUC, blinding of participants and therapists is not possible.

\section{Box 1 Inclusion and exclusion criteria}

\section{Inclusion criteria}

1. Bodily distress syndrome, multiorgan type of at least 12 months duration.

2. 15-19-year-olds at referral.

3. Raised since infancy in Denmark or born to Danish parents. Understand, speak and read Danish.

4. Moderate or severe impairment.

Exclusion criteria

1. Not completing informed consent.

2. Acute psychiatric disorder demanding other treatment, or if the patient is suicidal.

3. A lifetime diagnosis of psychosis, mania or depression with psychotic symptoms (International Classification of Diseases, 10th Revision (ICD-10): F20-29, F30-31, F32.2, F33.3), serious cognitive deficits or developmental disorders such as mental retardation and autism (ICD-10: F70, F84).

4. Substance abuse of, for example, narcotics, alcohol or medication.

5. Pregnancy at the time of inclusion.

6. Not suitable for group-based treatment, for example, patients with severe ADHD (ICD-10: F90), severe social phobia (ICD-10: F40.1) or conduct disorder (ICD-10: F91).

\section{INTERVENTIONS}

\section{Enhanced usual care}

Patients allocated to EUC will have a psychiatric consultation of $1 \frac{1 / 2}{2}$ hours duration, $\sim 2$ weeks after clinical assessment, with participation of the patient and his/her parents or close relatives. The consultation is manualised and includes psychoeducation related to the diagnosis of multiorgan BDS, health promoting strategies, advice on medication or other treatment, supplemented with written information on the BDS diagnosis and general recommendations. ACT elements are not incorporated or used in the consultation. The aim of the consultation is to increase the family's understanding of BDS and to optimise management in primary care and social services support by an individualised treatment plan sent to the patient's GP. The consultation is carried out by the child and adolescent psychiatrist doing the initial assessment.

\section{ACT-based group therapy}

Patients allocated to ACT-based group therapy receive the same psychiatric consultation as described above, before starting the manualised ACT treatment developed specifically for this patient group. The therapy is given in groups of 7-8 patients with nine modules (ie, 27 hours in total) over a period of 3 months and one follow-up meeting (3 hours) 3 months after module 9. Detailed information on the treatment programme is presented in figure 2. The parents and other relevant close relatives (eg, siblings, boyfriends/girlfriends) are invited to participate in an information meeting, to support their resources to help the adolescent improve his/her functional level and ability to cope with the 
symptoms. One individual consultation with the adolescent and close relatives is offered shortly after module 8. After completed ACT therapy, an individualised treatment plan is sent to the patient's GP.

Patients assigned to ACT therapy have to agree not to have any other psychological treatment for BDS while in therapy.

\section{Therapist training and adherence to treatment manual}

Therapists are child and adolescent psychiatrists and psychologists with specialist training in ACT. Clinicians well experienced in ACT and group therapy supervise the treatment. Sessions are videotaped and assessed by an external panel to ensure adherence to the treatment manual.

\section{Compliance and attrition}

Treatment compliance is assessed by recording the number of completed ACT modules. When applicable, participants are asked for their reasons for poor compliance or dropout. In the case of dropout from the ACT group therapy, data collection continues as planned with the patients' consent.

\section{OUTCOME MEASURES}

Outcome measures are obtained at six different time points: at baseline (ie, before assessment and randomisation) and at 2, 4, 6, 8 and 12 months after randomisation. These time points have been designed to follow the time schedule of the ACT group therapy to allow for evaluation of process variables. Figure 1 depicts how these time points relate to assessment and treatment. Primary and secondary outcome measures are assessed by web-based questionnaires (table 2). The questionnaies are distributed simultaneously to all patients within the randomised blocks regardless of treatment group. The primary end point is 12 months after randomisation.
Owing to a study population of adolescents approaching adulthood (15+ years), questionnaires developed and tested in adults are chosen.

Three questionnaires (Limitation Index (LI), ${ }^{52}$ Avoidance and Fusion Questionnaire in Youth (AFQ-Y8), ${ }^{53}$ and Psychological Inflexibility in Pain Scale (PIPS-12) ${ }^{54}$ ) have been translated with reference to standard procedures with initial translation, synthesis of translations and back-translation. ${ }^{55}$

\section{Primary outcome}

The primary outcome is improvement in physical health 12 months after randomisation, measured with an aggregate score of the Short Form Health Survey (SF-36) subscales physical functioning (PF), bodily pain (BP) and vitality (VT) ${ }^{56}{ }^{57}$ with a score range from 15 to 65 . This score has previously been used as the primary outcome in a comparable trial in adults ${ }^{39}$ due to well-known psychometric problems with the existing physical component score $(\mathrm{PCS})^{73}$ and based on the rationale that these three subscales have shown to be key domains affected in this patient group. ${ }^{74}$ Danish norm data for adolescents are available. ${ }^{56}$

\section{Self-reported secondary outcomes}

Illness severity is measured by two questionnaires. (1) The Somatisation subscale of the Symptom Checklist Revised-90 ${ }^{58}{ }^{61}$ (12 items, 5-point scale), a widely used symptom checklist of commonly experienced physical symptoms. (2) The BDS checklist ${ }^{59}$ (25 items, 5-point scale), a symptom checklist added as a new measure for validation in adolescents. It is developed from the symptoms stated in the BDS criteria, hence evaluating symptom severity in four symptom groups.

The impact of symptoms on functioning, that is, symptom interference, is evaluated by self-report and parent report using the LI. ${ }^{44}{ }^{52} \mathrm{LI}$ is a modified version of the Pain Interference Index (PII) (6 items, 7-point scale), a validated questionnaire for children and

Figure 2 Overview of the group-based acceptance and commitment therapy treatment programme. The overall focus of the treatment is to increase the patients' physical and emotional self-awareness, and to teach them skills to manage the distress associated with difficult thoughts, emotions and bodily sensations. Practical exercises throughout the treatment include experiential exercises focusing on identification of own values, barriers and avoidance behaviour, and mindfulness exercises focusing on allowance of the experience of here and now as it is and of being present. Gradual exposure is implemented through individually customised homework assignments in accordance with the identified personal values. BDS, bodily distress syndrome. 
Table 2 Outcome measures

\section{Months}

Instrument

\begin{tabular}{llllll}
\hline 0 & 2 & 4 & 6 & 8 & 12
\end{tabular}

\section{Respondent: $\mathrm{X}=$ Patient; $\mathrm{P}=$ Parent \\ Primary outcome}

Physical health

Secondary outcomes

Illness severity

Symptom interference

Depression and anxiety score

Mental health

Illness worry

Perceived stress

Overall impression of change

Process measures

IIIness perception

Illness related behaviour

Psychological flexibility

SF-36 5657

SCL-Som ${ }^{58}$

BDS checklist ${ }^{59}$

$\mathrm{LI}^{52}$

SCL-8-6-4 ${ }^{58}$ 60-62

SF-36 5657

Whiteley- $7^{63}$

PSS $^{64}$

$\mathrm{PGIC}^{65}$

$\begin{array}{llllll}x & X & X & x & x & X\end{array}$

Potential moderators

Family functioning

Attachment style

Negative life events

Physiological measures

HRV

$\mathrm{BIPQ}{ }^{66}$

$B R I Q^{67}$

AFQ-Y $8^{53}$

PIPS- $12^{54}$

$F A D^{68}$

ECR-RS $^{69}$

Negative life events ${ }^{70}$

$\begin{array}{llllll}X & X & X & X & X & X \\ X & X & X & X & X & X \\ X & & & & & X \\ X P & & & X P & X & X P \\ X & & & X & X & X \\ X & X & X & X & X & X \\ X & X & X & X & X & X \\ X & & & & & X\end{array}$

Hair cortisol

HRV measured with the Vagus device

(resting state, standing, slow breathing, valsalva) ${ }^{71}$

Measurement of hair cortisol in 2 strands of hair

closest to the scalp $(1-2 \mathrm{~cm})$

Inflammatory response

IL-6, TNF- $\alpha$, high-sensitive CRP, IL-1, neopterin,

CD163, HO1, MCP1

Accelerometer (Actigraph wGT3X-BT) worn for

7 consecutive days ${ }^{72}$

\section{Physical activity}

AFQ-Y8, Avoidance and Fusion Questionnaire for Youth; BDS, bodily distress syndrome; BIPQ, Brief IIIness Perception Questionnaire; BRIQ, Behavioural Responses to IIIness Questionnaire; CRP, C reactive protein; ECR-RS, Experience in Close Relationships-Relationship

Structure; FAD, Family Assessment Device (general functioning subscale); HO1, heme oxygenase-1; HRV, heart rate variability; IL-6,

interleukin 6; LI, Limitation Index (Revised from Pain Interference Index); MCP1, monocyte chemoattractant protein-1; P, parent; PGIC, Patient

Global Impression of Change; PIPS-12, Psychological Inflexibility in Pain Scale; PSS, Perceived Stress Scale; SCL-8-6-4, Symptom Checklist

Revised-90-depression and anxiety subscales; SCL-som, Symptom Checklist Revised-90—somatisation subscale; SF-36, Short Form

Health Survey; TNF- $\alpha$, tumour necrosis factor- $\alpha$; X, patient.

adolescents measuring the impact of pain in performing everyday activities and impact on, for example, mood and sleep. The modification from PII to LI is limited and represents a change in wording from 'pain' to 'symptoms'. Self-reported degree of absence from school or work is being registered.

Assessing symptoms of anxiety and depression brief versions of the corresponding subscales from Symptom Checklist Revised-90 are used (SCL-8, SCL-6, SCL-4 $)^{58} 60-62$ (13 items in total, 5 point scale). Level of illness worry is measured by Whiteley- $7^{63}$ ( 7 items, 5-point scale), a subscale of the Whiteley Index. Mental health is measured with the Mental Component Summary (MCS) from SF-36. ${ }^{56} 57$

Subjective perception of stress is measured by the Perceived Stress Scale (PSS) ${ }^{64}{ }^{75}$ (10 items, 5-point scale). The scale is a widely used measure of the degree to which situations in life are perceived as stressful. Danish norm data for adolescents are available.
The overall impression of improvement is measured with the Patient Global Impression of Change (PGIC) ${ }^{65}$ (1 item, 7-point scale). Answers range from 'no change (or condition has gotten worse)' to 'a great deal better and a considerable improvement that has made all the difference'.

\section{Process measures}

The process measures evaluate specific areas hypothesised to play a role in the development and perpetuation of functional somatic symptoms, and are hence addressed directly in the treatment.

Illness perception is measured by the Brief Illness Perceptions Questionnaire (BIPQ) ${ }^{66}$ (8 items, 10-point scale and additional item regarding cause of symptoms) which has been widely used in a range of illnesses. The perception of five core components (identity, cause, timeline, consequence and cure-control) is evaluated as they together form the perception of illness. In a 
comparable study with adults, changes in illness perceptions partly mediated the effect of treatment on outcome. $^{76}$

Illness-related behaviour is measured by the Behavioural Responses to Illness Questionnaire $(B R I Q)^{67}$ (13 item, 5-point scale). Specific illness-related behaviours have shown to be risk factors for development of FSS in adults. ${ }^{67}$

Psychological flexibility is an area specifically targeted in ACT. It is measured by the AFQ-Y8 ${ }^{53}$ (8 items, 5-point scale) and PIPS-12 $2^{54}$ (12 items, 7-point scale).

\section{Potential predictors and moderators}

Relevant demographic data and potential important predictors for outcome, for example, predisposition to functional syndromes and number and kind of life events, are obtained as part of the diagnostic assessment. ${ }^{70}$

Family functioning is assessed by the subscale on general functioning from the Family Assessment Device $(\mathrm{FAD})^{68} 77$ (12 items, 4-point scale). In addition, the patient's attachment style is assessed dimensionally by Experience in Close Relationships-Relationship Structure (ECR-RS) ${ }^{69}$ (9 items, 7-point scale).

Credibility regarding treatment is assessed before the individual standard psychiatric consultation. ${ }^{78}$ At end of treatment, that is, after module 9, the participants complete a standard questionnaire regarding their experience of the service at the clinic.

Concomitant treatment and serious adverse events during the trial period will be registered by self-report 1 year after randomisation.

\section{Physiological measures}

Bodily stress response is assessed with three different measures pretreatment and post-treatment:

1. Heart rate variability as an indirect measure of the balance between the sympathetic and parasympathetic system. It is measured in various standardised situations (resting state, standing, slow breathing and valsalva) with the handheld device Vagus. ${ }^{16} 7179$

2. Hair cortisol as a biological marker for long-term bodily stress. It is measured from two strands of hair cut close to the scalp, since the proximal $1 \mathrm{~cm}$ segment of hair represents the cortisol level of the past month. ${ }^{80}$

3. Biomarkers for inflammatory and oxidative stress (including interleukin 6 (IL-6), tumour necrosis factor- $\alpha$, high-sensitive $\mathrm{C}$ reactive protein, IL-1, neopterin, CD163, heme oxygenase-1 (HO1), monocyte chemoattractant protein-1 (MCP1) as well as newer proteo-based markers). ${ }^{81-84}$

\section{Physical activity}

Level of physical activity is assessed pretreatment and post-treatment by anthropometric measurements with an accelerometer (Actigraph wGT3X-BT). ${ }^{72}$ The accelerometer is worn on the right hip 24 hours-a-day for seven consecutive days.
A specific protocol for evaluation of physiological measures and physical activity will be made specifying hypotheses and analytical strategies. A large ongoing epidemiological study in Denmark (DanFunD) will be available for later comparison of results. ${ }^{85}$

\section{SAMPLE SIZE ESTIMATION}

Power estimation is based on the primary hypothesis regarding changes in self-reported physical health measured with the SF-36 aggregate score. Given the efficacy in a previous RCT study of ACT in adolescents with chronic functional pain ${ }^{44}$ as well as data on a subgroup of patients under 30 years from another RCT study of CBT with BDS, ${ }^{39}$ an improvement of self-reported physical health is estimated to be maximum three points (from 39 to 42) in the control group and at least five points (from 39 to 44) in the ACT group from baseline to 12 months after randomisation. The baseline value assumes an SD of 8 referring to the defined groups of patients. Using a random-effects model in a simulation setting shows that in order to statistically detect such a difference in improvement (test of no interaction), given a two-sided $\alpha$ of 0.05 and with $95 \%$ power, we need to allocate 60 patients to each group.

\section{STATISTICAL ANALYSIS}

The efficacy of the ACT treatment will be evaluated on an intention-to-treat basis by means of random-effects model regression analysis adjusted for prognostic important baseline characteristics. The main efficacy analysis will pertain to the data obtained at 12 months follow-up. Baseline characteristics will be tabulated by treatment modality in order to evaluate success of randomisation. To judge possible bias due to missing data, a random-effect model on multiple imputed data will be performed.

An explorative mediation analysis will be performed to investigate to what extent the intervention can affect the primary outcome through each of the process measures. The analytical strategy previously used in a large-scale trial will be used. ${ }^{86}$

\section{DISSEMINATION}

Results will be reported according to the CONSORT statement for non-pharmacological interventions, ${ }^{87}$ and will be submitted for publication in peer-reviewed English language journals. Positive, inconclusive and negative findings will be published. Trial findings will also be disseminated through conference abstracts.

\section{DATA MONITORING AND MANAGEMENT}

This trial is considered a minimal risk study and hence a data and monitoring committee has not been established. Questionnaires are administered electronically and saved in an online database. The database is secured with a password-protected access system, and 
access to files is limited to research staff that requires direct access. Baseline information obtained during assessment is registered in a Case Report Form (CRF). All CRFs are stored in locked file cabinets in areas with limited access.

\section{DISCUSSION}

Adolescents with FSS are at risk of continuity of physical problems into adulthood implying reduced quality of life due to potential functional impairment, social withdrawal, lack of education and incapacity to work. To the best of our knowledge, this study will be one of the first larger randomised clinical trials, evaluating the efficacy of a group-based treatment for adolescents with a range of FSS grouped under the unifying diagnosis of multiorgan BDS compared with EUC.

Our study design has some limitations. First is the lack of comparison with an evidence-based control treatment. However, since the aim of this study is to compare ACT group therapy to the best treatment available (ie, EUC), we use a pragmatic design that offers systematic clinical assessment and an individual treatment plan also to patients in the usual care arm. Also, a unified treatment for adolescents with a range of FSS has not been tested before. Second, blinding is not possible to the clinician providing the standard psychiatric consultation. However, this is a general problem in trials of behavioural interventions. Third, the study design does not allow us to determine which treatment components are most important in achieving change. Accordingly, our aim is to assess whether the whole complex intervention as delivered is more effective than EUC in improving physical health. Fourth, the assessment and treatment are carried out in a specialised setting, which might not guarantee that the treatment, if proven successful, will work in everyday clinical practice across different populations, clinical contexts, etc. Finally, the results from the study cannot automatically be applied to younger adolescents given the developmental perspective, with multiple symptoms being less common in children and younger adolescents.

Important strengths of the study are the evaluation of potential psychosocial and biological predictors and moderators of outcomes. Furthermore, all patients are given a thorough assessment providing them with a positive and evidence-based understanding of their illness, ${ }^{88} 89$ and the treatment model is developed based on treatments with proven effect for both paediatric and adult patients with FSS and related disorders. ${ }^{39} 4044$

Bias is minimised by the use of a manualised treatment, different therapists, valid outcome measures, multiple assessment points and by predefining and publishing all outcome measures before study start.

Anticipated difficulties conducting the study include recruitment problems due to stringent inclusion and exclusion criteria as well as lack of knowledge of available service for adolescents and social prejudices in terms of receiving psychiatric diagnosis and psychological treatment for functional symptoms. ${ }^{8}$

In conclusion, this study will provide important information about efficacy, processes of change and moderators. If the treatment is successful, it will improve the quality of life of adolescents with FSS and may, over the life course, lead to substantial savings in both healthcare costs and societal costs.

\section{Author affiliations}

${ }^{1}$ Research Clinic for Functional Disorders and Psychosomatics, Aarhus University Hospital, Aarhus, Denmark

${ }^{2}$ Behavior Medicine Pain Treatment Services, Karolinska, Stockholm, Sweden ${ }^{3}$ Regional Centre for Child and Adolescent Psychiatry, Risskov, Aarhus University Hospital, Aarhus, Denmark

Contributors KHK took part in designing of the study, drafted the initial manuscript and prepared the final manuscript as submitted. AS took part in developing the research idea and in designing of the study, contributed with data for statistical power analysis and critically revised the manuscript. RKW took part in designing of the study, contributed with data for statistical power analysis and critically revised the manuscript. PF took part in developing of the research idea and critically revised the manuscript. EØ took part in the statistical design of the study, made the power analysis and description of the statistical method and critically revised the manuscript. CUR came up with the original research idea, took part in designing of the study, drafted the initial treatment protocol and critically revised the manuscript. All the authors approved the final manuscript as submitted and agree to be accountable for all aspects of the work.

Funding This study is supported by TrygFonden (grant number 100408) and the Danish Medical Associations Research Fund (grant number 2013-5480/ 912523-63).

Disclaimer None of the funding sources have authority over any of the study activities.

\section{Competing interests None declared}

Ethics approval The project will be conducted in accordance with Helsinki Declaration II. Approval has been obtained from the Science Ethics Committee of the Central Denmark Region (journal number 1-10-72-181-14) and the Danish Data Protection (reference number 2007-58-0010; application number 1-16-02-290-14).

Provenance and peer review Not commissioned; externally peer reviewed.

Open Access This is an Open Access article distributed in accordance with the Creative Commons Attribution Non Commercial (CC BY-NC 4.0) license, which permits others to distribute, remix, adapt, build upon this work noncommercially, and license their derivative works on different terms, provided the original work is properly cited and the use is non-commercial. See: http:// creativecommons.org/licenses/by-nc/4.0/

\section{REFERENCES}

1. Korterink JJ, Diederen K, Benninga MA, et al. Epidemiology of pediatric functional abdominal pain disorders: a meta-analysis. PLOS ONE 2015;10:e0126982.

2. Kashikar-Zuck S, Ting TV. Juvenile fibromyalgia: current status of research and future developments. Nat Rev Rheumatol 2014;10:89-96.

3. Nijhof SL, Maijer K, Bleijenberg G, et al. Adolescent chronic fatigue syndrome: prevalence, incidence, and morbidity. Pediatrics 2011;127:e1169-75.

4. Garralda ME. Unexplained physical complaints. Pediatr Clin North Am 2011;58:803-13, ix.

5. Vila M, Kramer T, Hickey N, et al. Assessment of somatic symptoms in British secondary school children using the Children's Somatization Inventory (CSI). J Pediatr Psychol 2009;34:989-98. 
6. Eminson DM. Medically unexplained symptoms in children and adolescents. Clin Psychol Rev 2007;27:855-71.

7. Härmä AM, Kaltiala-Heino R, Rimpelä M, et al. Are adolescents with frequent pain symptoms more depressed? Scand J Prim Health Care 2002;20:92-6.

8. Garralda ME, Rask CU. Somatoform and related disorders. In: Thapar A, Pine DS, Leckman JF, et al, eds. Rutter's child and adolescent psychiatry. 6th edn. Wiley-Blackwell, 2015:1038.

9. Kashikar-Zuck S, Cunningham N, Sil S, et al. Long-term outcomes of adolescents with juvenile-onset fibromyalgia in early adulthood. Pediatrics 2014;133:e592-600.

10. Horst S, Shelby G, Anderson J, et al. Predicting persistence of functional abdominal pain from childhood into young adulthood. Clin Gastroenterol Hepatol 2014;12:2026-32.

11. Steinhausen HC, Winkler Metzke C. Continuity of functional-somatic symptoms from late childhood to young adulthood in a community sample. J Child Psychol Psychiatry 2007;48:508-13.

12. Perquin CW, Hunfeld JA, Hazebroek-Kampschreur AA, et al. Insights in the use of health care services in chronic benign pain in childhood and adolescence. Pain 2001;94:205-13.

13. Janssens KA, Oldehinkel AJ, Verhulst FC, et al. Symptom-specific associations between low cortisol responses and functional somatic symptoms: the TRAILS study. Psychoneuroendocrinology 2012;37:332-40.

14. Tak LM, Janssens KA, Dietrich A, et al. Age-specific associations between cardiac vagal activity and functional somatic symptoms: a population-based study. Psychother Psychosom 2010;79:179-87.

15. Meeus M, Nijs J. Central sensitization: a biopsychosocial explanation for chronic widespread pain in patients with fibromyalgia and chronic fatigue syndrome. Clin Rheumatol 2007;26:465-73.

16. Papadopoulos AS, Cleare AJ. Hypothalamic-pituitary-adrenal axis dysfunction in chronic fatigue syndrome. Nat Rev Endocrinol 2011;8:22-32.

17. Schröder A, Fink P. Functional somatic syndromes and somatoform disorders in special psychosomatic units: organizational aspects and evidence-based treatment. Psychiatr Clin North Am 2011;34:673-87.

18. Grøholt EK, Stigum H, Nordhagen R, et al. Recurrent pain in children, socio-economic factors and accumulation in families. Eur J Epidemiol 2003;18:965-75.

19. Oster J. Recurrent abdominal pain, headache and limb pains in children and adolescents. Pediatrics 1972;50:429-36.

20. Perquin CW, Hazebroek-Kampschreur AA, Hunfeld JA, et al. Pain in children and adolescents: a common experience. Pain 2000;87:51-8.

21. Rask CU, Ørnbøl E, Fink PK, et al. Functional somatic symptoms and consultation patterns in 5- to 7-year-olds. Pediatrics 2013;132 e459-67.

22. Budtz-Lilly A, Schröder A, Rask MT, et al. Bodily distress syndrome: a new diagnosis for functional disorders in primary care? BMC Fam Pract 2015;16:180.

23. Creed FH, Tomenson B, Chew-Graham C, et al. Multiple somatic symptoms predict impaired health status in functional somatic syndromes. Int J Behav Med 2013;20:194-205.

24. Rask M, Ørnbøl E, Rosendal M, et al. Long-term outcome of bodily distress syndrome in primary care: a follow-up study on healthcare costs, work disability, and self-rated health. Psychoso Med. In press. doi:10.1097/PSY.0000000000000405

25. Fink P, Toft T, Hansen MS, et al. Symptoms and syndromes of bodily distress: an exploratory study of 978 internal medical, neurological, and primary care patients. Psychosom Med 2007;69:30-9.

26. Fink P, Schröder A. One single diagnosis, bodily distress syndrome, succeeded to capture 10 diagnostic categories of functional somatic syndromes and somatoform disorders. J Psychosom Res 2010;68:415-26.

27. Glombiewski JA, Sawyer AT, Gutermann J, et al. Psychological treatments for fibromyalgia: a meta-analysis. Pain 2010;151:280-95.

28. White PD, Goldsmith KA, Johnson AL, et al. Comparison of adaptive pacing therapy, cognitive behaviour therapy, graded exercise therapy, and specialist medical care for chronic fatigue syndrome (PACE): a randomised trial. Lancet 2011;377:823-36.

29. Kleinstäuber M, Witthöft M, Hiller W. Efficacy of short-term psychotherapy for multiple medically unexplained physical symptoms: a meta-analysis. Clin Psychol Rev 2011;31:146-60.

30. Zijdenbos IL, de Wit NJ, van der Heijden GJ, et al. Psychological treatments for the management of irritable bowel syndrome. Cochrane Database Syst Rev 2009;(1):CD006442.

31. Husain K, Browne T, Chalder T. A review of psychological models and interventions for medically unexplained somatic symptoms in children. Child Adolesc Ment Health 2007;12:2-7.

32. Levy RL, Langer SL, Walker LS, et al. Cognitive-behavioral therapy for children with functional abdominal pain and their parents decreases pain and other symptoms. Am J Gastroenterol 2010;105:946-56.

33. Robins PM, Smith SM, Glutting JJ, et al. A randomized controlled trial of a cognitive-behavioral family intervention for pediatric recurrent abdominal pain. J Pediatr Psychol 2005;30:397-408.

34. Nijhof SL, Bleijenberg G, Uiterwaal CS, et al. Effectiveness of internet-based cognitive behavioural treatment for adolescents with chronic fatigue syndrome (FITNET): a randomised controlled trial. Lancet 2012;379:1412-18.

35. Palermo TM, Eccleston C, Lewandowski AS, et al. Randomized controlled trials of psychological therapies for management of chronic pain in children and adolescents: an updated meta-analytic review. Pain 2010;148:387-97.

36. Kashikar-Zuck S, Swain NF, Jones BA, et al. Efficacy of cognitive-behavioral intervention for juvenile primary fibromyalgia syndrome. J Rheumatol 2005;32:1594-602.

37. Schröder A, Sharpe M, Fink P. Medically unexplained symptom management. Lancet Psychiatry 2015;2:587-8.

38. Fink $\mathrm{P}$, Burton $\mathrm{C}$, de Bie $\mathrm{J}$, et al. Current state of management and organisation of care in Medically unexplained symptoms, somatisation and bodily distress. In: Creed F, Henningsen P, Fink P, eds. Developing better clinical services. Cambridge: Cambridge University Press, 2011.

39. Schröder A, Rehfeld E, Ornbøl E, et al. Cognitive-behavioural group treatment for a range of functional somatic syndromes: randomised trial. Br J Psychiatry 2012;200:499-507.

40. Fjorback LO, Arendt M, Ornbøl E, et al. Mindfulness therapy for somatization disorder and functional somatic syndromes: randomized trial with one-year follow-up. J Psychosom Res 2013;74:31-40.

41. Plante WA, Lobato D, Engel R. Review of group interventions for pediatric chronic conditions. J Pediatr Psychol 2001;26:435-53.

42. Kichler JC, Kaugars AS, Marik P, et al. Effectiveness of groups for adolescents with type 1 diabetes mellitus and their parents. Fam Syst Health 2013;31:280-93.

43. Clarke GN, DeBar LL. Group cognitive-behavioral treatment for adolescent depression. In: Weisz J, Kazdin A, eds. Evidence-based psychotherapies for children and adolescents. 2nd edn. New York: The Guilford Press, 2010:111, 112, 121.

44. Wicksell RK, Melin L, Lekander M, et al. Evaluating the effectiveness of exposure and acceptance strategies to improve functioning and quality of life in longstanding pediatric pain-a randomized controlled trial. Pain 2009;141:248-57.

45. Gauntlett-Gilbert J, Connell H, Clinch J, et al. Acceptance and values-based treatment of adolescents with chronic pain: outcomes and their relationship to acceptance. $J$ Pediatr Psychol 2013;38:72-81.

46. Hayes SC, Bissett RT, Korn Z, et al. The impact of acceptance versus control rationales on pain tolerance. Psychol Rec 2012;49:3.

47. McCracken LM, Eccleston C. Coping or acceptance: what to do about chronic pain? Pain 2003;105:197-204.

48. Hayes SC, Luoma JB, Bond FW, et al. Acceptance and commitment therapy: model, processes and outcomes. Behav Res Ther 2006;44:1-25.

49. Van Houdenhove B, Luyten P. Customizing treatment of chronic fatigue syndrome and fibromyalgia: the role of perpetuating factors. Psychosomatics 2008;49:470-7.

50. Wing JK, Babor T, Brugha T, et al. SCAN: Schedules for Clinical Assessment in Neuropsychiatry. Arch Gen Psychiatry 1990;47:589-93.

51. Goodman R, Ford $\mathrm{T}$, Richards $\mathrm{H}$, et al. The Development and Well-Being Assessment: description and initial validation of an integrated assessment of child and adolescent psychopathology. J Child Psychol Psychiatry 2000;41:645-55.

52. Holmström L, Kemani MK, Kanstrup M, et al. Evaluating the Statistical Properties of the Pain Interference Index in Children and Adolescents with Chronic Pain. J Dev Behav Pediatr 2015;36:450-4.

53. Greco LA, Lambert W, Baer RA. Psychological inflexibility in childhood and adolescence: development and evaluation of the Avoidance and Fusion Questionnaire for Youth. Psychol Assess 2008;20:93-102.

54. Wicksell RK, Lekander M, Sorjonen K, et al. The Psychological Inflexibility in Pain Scale (PIPS) - statistical properties and model fit of an instrument to assess change processes in pain related disability. Eur J Pain 2010;14:771.e1-14.

55. Beaton DE, Bombardier C, Guillemin F, et al. Guidelines for the process of cross-cultural adaptation of self-report measures. Spine (Phila Pa 1976) 2000;25:3186-91.

56. Bjørner J, Damsgaard M, Watt T, et al. Dansk manual til SF-36: Et spørgeskema om helbredsstatus. Danish Manual. 1997. 
57. Bjorner JB, Damsgaard MT, Watt T, et al. Tests of data quality, scaling assumptions, and reliability of the Danish SF-36. J Clin Epidemiol 1998;51:1001-11.

58. Derogatis LR, Cleary PA. Confirmation of the dimensional structure of the SCL-90: a study in construct validation. J Clin Psychol 1977;33:981-9.

59. Budtz-Lilly A, Fink P, Ørnbøl E, et al. A new questionnaire to identify bodily distress in primary care: the 'BDS checklist'. J Psychosom Res 2015;78:536-45.

60. Fink P, Ørnbøl E, Huyse FJ, et al. A brief diagnostic screening instrument for mental disturbances in general medical wards. $J$ Psychosom Res 2004:57:17-24.

61. Derogatis LR. SCL-90-R: Vejledning til administration og scoring. Danish Manual. 1994.

62. Christensen KS, Bech P, Fink P. Measuring mental health by questionnaires in primary care-unidimensionality, responsiveness and compliance. Eur Psychiatr Rev 2010;3:8-12.

63. Fink $\mathrm{P}$, Ewald $\mathrm{H}$, Jensen $\mathrm{J}$, et al. Screening for somatization and hypochondriasis in primary care and neurological in-patients: a seven-item scale for hypochondriasis and somatization. J Psychosom Res 1999;46:261-73.

64. Lee EH. Review of the psychometric evidence of the Perceived Stress Scale. Asian Nurs Res (Korean Soc Nurs Sci) 2012;6:121-7.

65. Hurst $\mathrm{H}$, Bolton J. Assessing the clinical significance of change scores recorded on subjective outcome measures. J Manipulative Physiol Ther 2004:27:26-35.

66. Broadbent E, Petrie KJ, Main J, et al. The brief illness perception questionnaire. J Psychosom Res 2006;60:631-7.

67. Spence M, Moss-Morris R, Chalder T. The Behavioural Responses to Illness Questionnaire (BRIQ): a new predictive measure of medically unexplained symptoms following acute infection. Psychol Med 2005;35:583-93.

68. Boterhoven de Haan KL, Hafekost J, Lawrence D, et al. Reliability and validity of a short version of the general functioning subscale of the McMaster Family Assessment Device. Fam Process 2015;54:116-23.

69. Fraley RC, Heffernan ME, Vicary AM, et al. The Experiences in Close Relationships-Relationship Structures Questionnaire: a method for assessing attachment orientations across relationships. Psychol Assess 2011;23:615-25.

70. Shevlin M, Elklit A. A latent class analysis of adolescent adverse life events based on a Danish national youth probability sample. Nord J Psychiatry 2008;62:218-24.

71. Vistisen ST, Hansen TK, Jensen J, et al. Heart rate variability in neurorehabilitation patients with severe acquired brain injury. Brain Inj 2014;28:196-202.

72. Romanzini M, Petroski EL, Ohara D, et al. Calibration of ActiGraph GT3X, Actical and RT3 accelerometers in adolescents. Eur J Sport Sci 2014;14:91-9.

73. Schroder A, Oernboel E, Licht RW, et al. Outcome measurement in functional somatic syndromes: SF-36 summary scores and some scales were not valid. J Clin Epidemiol 2012;65:30-41.
74. Mease P, Arnold LM, Bennett R, et al. Fibromyalgia syndrome. $J$ Rheumatol 2007;34:1415-25.

75. Cohen S, Kamarck T, Mermelstein R. A global measure of perceived stress. J Health Soc Behav 1983;24:385-96.

76. Christensen SS, Frostholm L, Ørnbøl E, et al. Changes in illness perceptions mediated the effect of cognitive behavioural therapy in severe functional somatic syndromes. J Psychosom Res 2015;78:363-70.

77. Epstein NB, Baldwin LM, Bishop DS. The McMaster Family Assessment Device. J Marital Fam Ther 1983:9:171-80.

78. Devilly GJ, Borkovec TD. Psychometric properties of the credibility/ expectancy questionnaire. J Behav Ther Exp Psychiatry 2000;31:73-86.

79. Tak LM, Riese $\mathrm{H}$, de Bock $\mathrm{GH}$, et al. As good as it gets? A meta-analysis and systematic review of methodological quality of heart rate variability studies in functional somatic disorders. Biol Psychol 2009;82:101-10.

80. Russell E, Koren G, Rieder M, et al. Hair cortisol as a biological marker of chronic stress: current status, future directions and unanswered questions. Psychoneuroendocrinology 2012;37:589-601.

81. Jeckel CM, Lopes RP, Berleze MC, et al. Neuroendocrine and immunological correlates of chronic stress in 'strictly healthy' populations. Neuroimmunomodulation 2010;17:9-18.

82. Euteneuer F, Schwarz MJ, Hennings A, et al. Psychobiological aspects of somatization syndromes: contributions of inflammatory cytokines and neopterin. Psychiatry Res 2012;195:60-5.

83. Maes M, Twisk FN, Kubera M, et al. Evidence for inflammation and activation of cell-mediated immunity in Myalgic Encephalomyelitis/ Chronic Fatigue Syndrome (ME/CFS): increased interleukin-1, tumor necrosis factor-alpha, PMN-elastase, lysozyme and neopterin. $J$ Affect Disord 2012;136:933-9.

84. Maes M, Twisk FN, Ringel K. Inflammatory and cell-mediated immune biomarkers in myalgic encephalomyelitis/chronic fatigue syndrome and depression: inflammatory markers are higher in myalgic encephalomyelitis/chronic fatigue syndrome than in depression. Psychother Psychosom 2012;81:286-95.

85. DanFunD Project [Internet]. 2016. http://www.danfund.org

86. Chalder T, Goldsmith KA, White PD, et al. Rehabilitative therapies for chronic fatigue syndrome: a secondary mediation analysis of the PACE trial. Lancet Psychiatry 2015;2:141-52.

87. Schulz KF, Altman DG, Moher D, CONSORT Group. CONSORT 2010 statement: updated guidelines for reporting parallel group randomized trials. Ann Intern Med 2010;152:726-32.

88. Rief W, Broadbent E. Explaining medically unexplained symptoms-models and mechanisms. Clin Psychol Rev 2007;27:821-41.

89. van Ravenzwaaij J, Olde Hartman $\mathrm{T}$, van Ravesteijn $\mathrm{H}$, et al Explanatory models of medically unexplained symptoms: a qualitative analysis of the literature. Ment Health Fam Med 2010;7:223-31. 